\title{
Work Values of Jordanian Fresh Graduates
}

\author{
Marwan Al-Zoubi ${ }^{1}$ \\ ${ }^{1}$ Department of Psychology, Faculty of Arts, University of Jordan, Amman, Jordan \\ Correspondence: Marwan Al-Zoubi, Department of Psychology, Faculty of Arts, University of Jordan, Amman \\ 11942, Jordan. Tel: 962-6535-5000 ext. 24977. E-mail: m.al-zoubi@ju.edu.jo
}

Received: November 4, 2015

Accepted: May 8, 2016

Online Published: June 18, 2016

doi:10.5539/ijbm.v11n7p237

URL: http://dx.doi.org/10.5539/ijbm.v11n7p237

\begin{abstract}
The aim of the study was to explore the work values of Jordanian fresh graduates as well as the effect of gender on values preferences. 1109 fresh university graduates participated in the study ( 720 females- $64.9 \%$, and 389 males). Participants completed a scale that assesses the level of importance of 10 work values. The results indicated that fresh graduates value jobs that provide them with career development, financial rewards, creativity, job security, teamwork, and opportunity to serve others while the least important values were for jobs that provide independence, prestige and excitement. Additionally, the results indicated that there are gender differences in work values preferences. The current study is providing helpful information for job counselors and career succession planners.
\end{abstract}

Keywords: work values, fresh graduate, career guidance

\section{Introduction}

Work values are preferences and needs related to working environment. These values are a part of a person's core beliefs and give meaning to the person's career and life. They represent the person beliefs about the level of desirability of various aspects of work such as the importance of pay, independence, teamwork, accomplishment, excitement, and prestige (Martin \& Osterling, 2014, Chen \& Kao, 2012; Lyons, Higgins, \& Duxbury, 2010; Allport, Vernon, \& Lindzey, 1960).

Values are a complex form of attitudes and beliefs and very helpful in the analysis of human behavior. Therefore, some researchers define values as general goals that an individual tries to attain (Super, 1995) while others indicted that work values is an organizing construct, which involves the priority placed on various aspects of work, jobs and the workplace (Elizur, 1984; Lyons, Higgins, \& Duxbury, 2010; Roe \& Ester, 1999).

It is widely recognized that values cannot be measured directly but rather can be rated by analyzing the preferences that a person considers important and have a value (Arnoled, 2005). Thus, self-rating methodology is widely used in identifying work values. Accordingly, many questionnaires and self-assessment tools have been developed such as Manhardt's (1972) Work Values Inventory, the Minnesota Importance Questionnaire (MIQ; Rounds, Dawis, Lofquist, \& Weis, 1981), Super's Work Values Inventory Revised (SWVI-R; Zytowski, 2006), and The Lyons Work Value Survey (LWVS; Lyons et al, 2010).

Despite many different labels, measures and conceptualizations, the various aspects included in the work values domain fall into two broad categories:

(1) Internal work values, which relate to person's preferences of personal growth such as career development, independence, ability to influence and control.

(2) External work values, which reflect issues related to work environment and policy such as pay, job security, serving others and opportunity for teamwork.

There are many benefits of identifying work values for new employees. Workplace values have proved to show a direct impact on work attitudes. Some studies indicated that work values are an important predictor of job satisfaction (Hegney, Plank, \& Parker, 2006; Froese \& Xiao, 2012) and organizational commitment (Howell, Kirk-Brown, \& Cooper, 2012).

Additionally, work values are important in career counseling and vocational guidance. Research indicated that values increase self-awareness and may influence career choices (Hirschi, 2008; Jin \& Rounds, 2012; Ros, Schwartz, \& Surkiss, 1999). For example if the person is considering a career change then understanding work 
values is critical to identifying a new career path.

It has widely recognized that values are not fixed components rather they change and develop. The changes in values have been observed in many countries across various job sectors and various cultures (Danis, Liu, \& Vacek, 2011). Values change has been attributed to several factors such as younger people attending university courses (Bayrkova, 2015). For example, research indicated that university life might change person's belief, attitudes, and values. Therefore, work values may be an important component of vocational guidance. Most universities' job centers are always surveying work values of university students as well as fresh graduates (Duffy \& Sedlacek, 2007; Fletcher \& Majour, 2004; Trintini \& Muzio, 1995).

According to factors affecting values, research indicated that there is a number of demographic and personal factors can affect work values such as gender, education, social and economic status, personality, family, and parents' nurturing style (Super, 1995). For instance, research indicted that there are differences among males and females in work preferences (Ryckman \& Houston, 2003). A study conducted by (Hagström \& Kjellberg, 2007) indicated that females rated Social relations and Altruism more important. Additionally, females' ratings of Benefits and career development and Influence were higher than males. Another study by (Byrakova, 2015) studied the work values of Bulgarian university students indicated that females scored higher than males on Advancement, Variety, Autonomy, Altruism, whereas males scored higher than females on Physical Prowess and Authority.

Finally, clarifying values is important because values are indications of the qualities people desire and seek in the activities in which they engage. Therefore, career guidance and counseling services in universities and governmental agencies measure frequently work values and preferences of students and fresh graduates in order to provide proper career guidance and career succession planning. Considering that Jordan is a developing country with high number of graduates then a survey research about work values is a necessity. Such research will provide information for career counselors and decision makers about students' interests, motivations, and attitudes toward work, and factors that influence their career choices. The current research is taking the initiative of exploring work values of Jordanian fresh gradates.

\section{Study Aims and Questions}

Based on the above, the current study has two purposes, the first purpose is to study the work values of Jordanian university fresh graduates and determine what the most and the least important work values are. Another objective is to decide whether there are gender differences in work values preferences. More specifically, the study aims to answer the following questions:

1) What are the work values of Jordanian fresh graduates (males and females) ordered from the most important to the least?

2) Does gender affect the work values preferences of fresh graduates?

\section{Methodology}

\subsection{Participants}

Participants were 1109 individuals. The average age is 23 years. $64.9 \%(n=720)$ of the total sample were females and $35.1 \%(n=389)$ were males. All participants were fresh university graduate (less than two years) and were unemployed in the time of data collection.

\subsection{Tools}

A special scale was developed for the purpose of this study. Considering literature review, aims of this study as well as the Jordanian culture and needs; a scale of work values were developed that measures 10 dimensions which are: (Service Orientation, Team Orientation, Influence, Creativity, Independence, Excitement, Career Development, Financial Rewards, Security, and Prestige). These dimensions were chosen based on a number of existed work values questionnaires such as Manhardt's (1972) Work Values Inventory, the Minnesota Importance Questionnaire (MIQ; Rounds, Dawis, Lofquist, \& Weis, 1981), Super's Work Values Inventory Revised, (SWVI-R; Zytowski, 2006), and The Lyons Work Value Survey (LWVS; Lyons et al, 2010). The scale was built on two factors: The first factor consists of five internal work values, which relate to person's preferences of personal growth, which are (influence, independence, career development, excitement, and control). The second factor consists of five external work values, which reflect issues related to work environment and policy (financial rewards, job security, service orientation, prestige and team orientation).

After piloting the initial version of the scale, the final version consists of 80 questions with 8 items for each dimension. Responses were indicated on a 5-point Likert style scale as follows: $(1=$ not important at all, $2=$ not 
important, 3 = neutral, $4=$ important, $5=$ very important). The total score of items related to each dimension presents the level of importance of the value, with a higher score indicating greater level of importance.

\subsubsection{Validity of the Work Values Scale}

The psychometric prosperities of the scale were extracted in an earlier pilot study and provided in a detailed report (Al-Zoubi, 2012). The results of the pilot study indicated that the scale has a content validity (the scale was validated by five psychologists and two HR mangers) and acceptable construct validity using items' inter-correlation and exploratory factor analysis. To ensure the validity of the scale, we examined the scale structure another time using Exploratory Factor Analysis (EFA) and sub-dimensions inter-correlation using the current data. First, common factor analysis with principal axis factoring and oblique rotation was used, which allowed the factors to be correlated. As shown in Table 1, a two-factor structure was identified by examining the scree plot and retaining factors with Eigenvalues greater than one. EFA of the set of the 10 work aspects produced two components (the internal work values and external work values). The factors model explained $51.88 \%$ of total variance. All items had loadings greater than $(0.60)$ which provide additional evidence of convergent validity.

Table 1. Exploratory factor analysis of the 10 work values scale $(\mathrm{N}=1109)$

\begin{tabular}{llll}
\hline Dimension & Intrinsic values & Extrinsic values & communalities \\
\hline Service orientation & & $\mathbf{0 . 7 6 2}$ & 0.646 \\
Team orientation & & $\mathbf{0 . 7 7 7}$ & 0.622 \\
Financial reward & & $\mathbf{0 . 6 2 4}$ & 0.749 \\
Job security & & $\mathbf{0 . 6 7 2}$ & 0.730 \\
Prestige & $\mathbf{0 . 8 8 4}$ & $\mathbf{0 . 4 5 2}$ & 0.560 \\
Excitement & $\mathbf{0 . 7 5 2}$ & & 0.669 \\
Career development & $\mathbf{0 . 4 9 3}$ & & 0.453 \\
Creativity & $\mathbf{0 . 6 2 5}$ & & 0.697 \\
Independence & $\mathbf{0 . 5 7 8}$ & & 0.671 \\
Influence & & 0.572 \\
\hline
\end{tabular}

Note. Loadings $<.40$ are not shown.

The next step analysis was exploring the inter-correlations between work values to explore the inter-correlations between dimensions which can be an indicator of structure validity of the scale. Table 2 provides the inter-correlations matrix of the 10 work values.

Table 2. Inter-Correlations between the 10 work values

\begin{tabular}{|c|c|c|c|c|c|c|c|c|c|c|}
\hline Dimension & 1 & 2 & 3 & 4 & 5 & 6 & 7 & 8 & 9 & 10 \\
\hline Service orientation & 1 & & & & & & & & & \\
\hline Team orientation & $.74 *$ & 1 & & & & & & & & \\
\hline Influence & $.65^{*}$ & $.60^{*}$ & 1 & & & & & & & \\
\hline Creativity & $.56^{*}$ & $.52 *$ & $.70^{*}$ & 1 & & & & & & \\
\hline Independence & $.44 *$ & $.47^{*}$ & $.58 *$ & $.24 *$ & 1 & & & & & \\
\hline Excitement & $.53 *$ & $.52 *$ & $.63^{*}$ & $.65^{*}$ & $.54^{*}$ & 1 & & & & \\
\hline Career development & $.41^{*}$ & $.48^{*}$ & $.48^{*}$ & $.58^{*}$ & $.41 *$ & $.42 *$ & 1 & & & \\
\hline Financial reward & $.29^{*}$ & $.34 *$ & $.43^{*}$ & $.32 *$ & $.45^{*}$ & $.34 *$ & $.36^{*}$ & 1 & & \\
\hline Job security & $.29 *$ & $.38^{*}$ & $.29 *$ & $.19^{*}$ & $.35^{*}$ & $.13 *$ & $.36^{*}$ & $.46^{*}$ & 1 & \\
\hline Prestige & $.39 *$ & $.41^{*}$ & $.58^{*}$ & $.40^{*}$ & $.50 *$ & $.44 *$ & $.32 *$ & $.55^{*}$ & $.35^{*}$ & 1 \\
\hline
\end{tabular}

** Correlation is significant at the 0.01 level (2-tailed).

The results in Table 2 indicate that all work values were positively inter-correlated. Some of the work values have strong correlations such as service orientation and teamwork orientation $(r=0.74)$ (i.e. internal work values), creativity and influence $(r=0.70)$ (i.e. external work values). However, other dimensions were poorly 
correlated such as job security and independence $(\mathrm{r}=0.13)$. These results indicate that the current questionnaire has sound convergent validity.

\subsubsection{Reliability of Work Values Questionnaire}

In terms of reliability, the $(b)$ coefficients indicated that the internal consistency of the sub-scales is acceptable $(b$ $=0.67-0.91)$. Table 3 provides results of the internal consistency coefficients for the 10 work values on the current sample using Cronpach Alpha formula.

Table 3. Internal consistency coefficients for the work values scale

\begin{tabular}{ll}
\hline Dimension name & $\boldsymbol{b}$ \\
\hline Service Orientation & 0.75 \\
Team Orientation & 0.71 \\
Influence & 0.76 \\
Creativity & 0.77 \\
Independence & 0.64 \\
Excitement & 0.74 \\
Career Development & 0.73 \\
Financial Rewards & 0.66 \\
Job Security & 0.60 \\
Prestige & 0.81 \\
\hline
\end{tabular}

\subsection{Procedures}

The sample was collected in 2013 by using local universities alumni records, advertisement in the local newspapers, formal websites and social media. Fresh graduates were informed of an opportunity to have a comprehensive assessment that may increase their awareness of their abilities and increase their employment chances. The comprehensive assessment consists of a full day assessment that includes completing various personality measures, cognitive tests, attitudes scales and behavioral assessments.

All tests and activities were completed in a special assessment center that contained 15 computers and a data show for instructions. Tests and questionnaires were applied in small groups ranging from 5-15 individuals. Three assistants were recruited to give instructions and supervise the procedures. All assistants received a comprehensive training to answer all participants' questions as well as administrate all tests and assessment activities. All instructions were included in a manual which became the standardized procedures for giving instructions and delivering assessment activities.

Individuals were asked to complete the work values scale along with other scales and tests. The scale was fully computerized (answering questions, marking and reporting). The scale took around 15 minutes to complete. Each individual participated in the assessment center received 10-page report about his/her potentials as well as a compensation for transportation (\$5).

\subsection{Statistical Analysis}

Statistical analysis was based on average and Standard Deviation (SD) for the raw scores of the work values subscales. Descriptive statistics were produced for all work values. The first question was answered by generating cross tabulation statistics (mean \& SD) and the second question was answered using independent samples T test.

\section{Results}

The aim of the study was to explore the work values of university fresh graduate as well as the effect of gender on values preferences. The following analysis presents the main results.

The first analysis was a descriptive one to show the mean and standard deviations of the sample according to their work values preferences. Table 4 provides means and standard deviations for the 10 values examined in this study using the total sample while tables 5 and 6 provide descriptive statistics for males and females samples separately. 
Table 4. Work values of the total sample ranked from the highest to lowest

\begin{tabular}{lllllll}
\hline Dimension & N & Minimum & Maximum & Mean & Std. Deviation & Rank \\
\hline Career Development & 1109 & 10 & 40 & 35.85 & 3.83 & First \\
Financial Rewards & 1109 & 10 & 40 & 32.81 & 2.95 & Second \\
Creativity & 1109 & 10 & 40 & 32.13 & 4.83 & Third \\
Security & 1109 & 10 & 40 & 32.02 & 2.53 & Forth \\
Team Orientation & 1109 & 10 & 40 & 31.95 & 4.12 & Fifth \\
Service Orientation & 1109 & 10 & 40 & 31.04 & 4.34 & Sixth \\
Influence & 1109 & 10 & 40 & 30.42 & 6.37 & Seventh \\
Independence & 1109 & 10 & 40 & 30.16 & 4.24 & Eighth \\
Prestige & 1109 & 10 & 40 & 27.91 & 5.23 & Ninth \\
Excitement & 1109 & 10 & 40 & 27.52 & 6.26 & Tenth \\
\hline
\end{tabular}

Table 5. Work values of the male sample ranked from the highest to lowest

\begin{tabular}{lllll}
\hline Dimension & $\mathbf{N}$ & Mean & Std. Deviation & Rank \\
\hline Career Development & 1109 & 36.30 & 3.37 & First \\
Security & 1109 & 34.68 & 2.48 & Second \\
Financial Rewards & 1109 & 33.60 & 2.84 & Third \\
Creativity & 1109 & 32.96 & 4.53 & Forth \\
Team Orientation & 1109 & 31.97 & 4.00 & Fifth \\
Influence & 1109 & 31.06 & 6.20 & Sixth \\
Service Orientation & 1109 & 31.00 & 4.35 & Seventh \\
Independence & 1109 & 29.81 & 4.36 & Eighth \\
Prestige & 1109 & 28.62 & 5.26 & Ninth \\
Excitement & 1109 & 27.91 & 5.97 & Tenth \\
\hline
\end{tabular}

Table 6. Work values of female sample ranked from the highest to the lowest

\begin{tabular}{lllll}
\hline Dimension & $\mathbf{N}$ & Mean & Std. Deviation & Rank \\
\hline Career Development & 1109 & 35.61 & 4.04 & First \\
Security & 1109 & 35.15 & 2.55 & Second \\
Financial Rewards & 1109 & 32.64 & 2.97 & Third \\
Team Orientation & 1109 & 31.93 & 4.19 & Forth \\
Creativity & 1109 & 31.67 & 4.92 & Fifth \\
Service Orientation & 1109 & 31.06 & 4.34 & Sixth \\
Independence & 1109 & 30.29 & 4.18 & Seventh \\
Influence & 1109 & 29.85 & 6.38 & Eighth \\
Prestige & 1109 & 27.53 & 5.17 & Ninth \\
Excitement & 1109 & 27.08 & 6.39 & Tenth \\
\hline
\end{tabular}

Tables 4-6 demonstrate the results of descriptive statistics of the work values scale. Means of the work values on the total sample ranged from 27 to 36 and standard deviations between 2.53 and 6.39. The most important work values for fresh graduates from the highest to the lowest were: career development $(\mathrm{M}=35.85, \mathrm{SD}=3.83)$, financial rewards $(\mathrm{M}=32.81, \mathrm{SD}=2.95)$ and creativity $(\mathrm{M}=32.13, \mathrm{SD}=4.83)$ while the least important values were for job that provide independence $(\mathrm{M}=30.16, \mathrm{SD}=4.24)$, prestige $(\mathrm{M}=27.91, \mathrm{SD}=5.23)$, and excitement $(\mathrm{M}=27.52, \mathrm{SD}=6.26)$.

Additionally, there were differences in the importance level of work values according to the sex of respondents. For example, males valued more influence and prestigious jobs in comparison with female sample while females valued higher level of independency. However, other dimensions have almost the same mean such as service orientation, teamwork orientation and service orientation.

The final analysis was about answering the second question of the study, which is about the effect of gender on work values preferences. Independent sample $T$ tests were used to answer the question and Table 7 provides the results of the analysis. 
Table 7. Results of $\mathrm{T}$ test analysis for the difference between females and males

\begin{tabular}{|c|c|c|c|c|c|}
\hline Dimension & Groups & $\mathbf{N}$ & Mean & T test & Mean difference \\
\hline \multirow[t]{2}{*}{ Service Orientation } & Male & 389 & 31.00 & 0.24 & 0.06 \\
\hline & Female & 720 & 31.06 & & \\
\hline \multirow[t]{2}{*}{ Team Orientation } & Male & 389 & 31.97 & 0.15 & 0.04 \\
\hline & Female & 720 & 31.93 & & \\
\hline \multirow[t]{2}{*}{ Influence } & Male & 389 & 46.60 & $4.58^{*}$ & 1.82 \\
\hline & Female & 720 & 44.78 & & \\
\hline \multirow[t]{2}{*}{ Creativity } & Male & 389 & 32.96 & $4.26^{*}$ & 1.28 \\
\hline & Female & 720 & 31.67 & & \\
\hline \multirow[t]{2}{*}{ Independence } & Male & 389 & 29.91 & $1.425-$ & 0.67 \\
\hline & Female & 720 & 30.29 & & \\
\hline \multirow[t]{2}{*}{ Excitement } & Male & 389 & 34.89 & $2.620^{*}$ & 1.03 \\
\hline & Female & 720 & 33.86 & & \\
\hline \multirow[t]{2}{*}{ Career Development } & Male & 389 & 36.30 & $2.883^{*}$ & 0.69 \\
\hline & Female & 720 & 35.61 & & \\
\hline \multirow[t]{2}{*}{ Financial Rewards } & Male & 389 & 21.00 & $3.866^{*}$ & 0.71 \\
\hline & Female & 720 & 20.29 & & \\
\hline \multirow[t]{2}{*}{ Security } & Male & 389 & 21.68 & $1.852-$ & 0.51 \\
\hline & Female & 720 & 21.97 & & \\
\hline \multirow[t]{2}{*}{ Prestige } & Male & 389 & 28.62 & $3.341^{*}$ & 1.09 \\
\hline & Female & 720 & 27.53 & & \\
\hline
\end{tabular}

* Significant at the 0.05 level (2-tailed).

The results in table 6 indicate that there are some significant differences in work values preferences between males and females. Six work values out of the ten values measured in the current study have significant differences. In all of the values that have significant differences, males preferred higher levels than females. The strongest difference was for the ability to influence as male preferred more influence ( $\mathrm{T}=4.58, \infty \leq 0.05$, mean difference $=1.82)$, followed by creativity $(\mathrm{T}=4.26, \infty \leq 0.05$, mean difference $=1.28)$, prestige $(\mathrm{T}=3.86, \infty \leq$ 0.05 , mean difference $=0.71)$, financial rewards $(\mathrm{T}=3.34, \infty \leq 0.05$, mean difference $=1.09)$, career development $(\mathrm{T}=2.88, \infty \leq 0.05$, mean difference $=0.69)$, and excitement $(\mathrm{T}=2.62, \infty \leq 0.05$, mean difference $=$ 1.03). However, the rest of work values have no significant differences.

\section{Discussion}

The aim of the study was to explore the work values of university fresh graduate in Jordan as well as the effect of gender on values preferences. The results of the study indicated that Jordanian who have recently graduated form university value the work that provide them with: fast career development, opportunity for financial rewards, opportunity to be creative, job security, opportunity to work as a team, and opportunity to serve others, while the least important values were for jobs that provide independence, prestige and excitement.

The order of the work values that young Jordanian graduates holds is representing the culture and economic and social circumstances in Jordan. Young generation in general is very ambitious to build up their career, skills and experience, therefore they value jobs that provide them with opportunity to build their skills, experiences and develop their careers. Additionally, most of fresh graduates in Jordan are unemployed and were supported financially by their parents. Therefore, they prefer jobs that provide them with financial rewards and security even if it without prestige. Additionally, university fresh graduates are shaped with globalization and new work trends so that, they hold values of teamwork and customer service orientation.

However, the unexpected work value that receives low importance was (excitement). In the normal cases, young generation always looking for excitement and looking for job that provide them with fun and excitement which reflect later on their involvement and motivation (Gahan, \& Abeysekera, 2009). However, Jordanian fresh graduates put this value in their least preferences (tenth) along with the value of prestige (ninth). These results may be interpreted by the economic and social situation of Jordanian job market. The unemployment in Jordan is very high and reached $14.7 \%$ according to the ministry of labor statistics in 2014 . Additionally, Jordan job market is full of refugees and foreign worker who compete Jordanians on jobs by taking lower wages. These high numbers of unemployment and competitiveness may pushed graduates to skip the preferences of job excitement and prestige and focus instead on jobs that provide them with career development, financial rewards 
and job security.

The other result in this study was about the differences in the importance level of work values according to the sex of respondents. In general, males valued more the ability to influence and prestigious jobs in comparison with females while females valued higher level of independency. In particular, the results of $\mathrm{T}$ test analysis indicated that six work values out of the ten values measured in the current study have significant differences. In all of the values that have significant differences, males preferred higher levels than females except the value of independency in which females valued more jobs with higher levels of independency. In the rest of the work values male valued more the ability to influence, ability to be creative prestigious jobs with opportunity of financial rewards, and jobs with more opportunity for career development.

These results are inline with previous research which indicates that males ask for more influence and authority and opportunity to be creative while females prefer higher level of independence and privacy (Bayrkova, 2015; Ryckman, \& Houston, 2003; Martin \& Osterling, 2014, Chen \& Kao, 2012; Lyons, Higgins, \& Duxbury, 2010; Hagström \& Kjellberg, 2007). However, Jordanian culture is a masculine one, and may affect our results and influence males to value jobs that have higher financial rewards as females are not expected to provide financial help to the family, like the western culture, but males are.

The current results provide some practical applications for fresh graduates' selection and career counseling. The current study indicates that fresh graduates can be selected based on their work values. Such results may help in selecting the right candidates as many studies indicated that work values could predict work performance especially the values of service orientation and teamwork (Cook, 2009). In addition, the current findings might be very helpful in career guidance. Fresh graduates usually look for different kinds of jobs and they are more open to various offers. Therefore, values profile may help career counselors to orient fresh graduates to jobs that suite their values and preferences.

Finally, the current study has several limitations, including: (a) measures variance as work values were measured using self assessment techniques (b) lack of generalizability beyond our population of interest (fresh university graduates). Given the different results reported by studies focusing on work values, future research is needed to measure other work values and other populations that may help to understand the reasons for, as well as the implications of, our findings.

\section{Acknowledgments}

The author would like to thank Innovation for Poverty Action (IPA), World Bank \& Business Development Center (BDC) for providing data for the current study.

\section{References}

Allport, G. W., Vernon, P. E., \& Lindzey, G. (1960). Study of values (3rd ed.). Boston, MA: Houghton-Mifflin.

Al-Zoubi, T. (2012). The psychometric properties of work values scale developed especially for Jordanian fresh graduates. Unpublished report presented to the Research and Economical Studies Department, World Bank.

Arnold, J., Silvester, J., Paterson, F., Roberston, I., Cooper, C., \& Burnes, B. (2005). Work Psychology. Understanding human behavior in the workplace (4th ed.). Prentice Hall, England.

Byrkova, S. (2015). Most Important Work Values in Bulgarian University Students. Psychological Thoughts, $8(1), 8-81$.

Chen, C. H. V., \& Kao, R. H. (2012). Work Values and Service-Oriented Organizational Citizenship Behaviors: The Mediation of Psychological Contract and Professional Commitment: A Case of Students in Taiwan Police College. Social Indicators Research, 107, 149-169.

Cook, M. (2009). Personnel selection, adding value through people (5th ed.). Wilely ltd. London.

Danis, W. M., Liu, L. A., \& Vacek, J. (2011). Values and upward influence strategies in transition: Evidence from the Czech Republic. Journal of Cross-Cultural Psychology, 42(2), 288-306. http://dx.doi.org/10.1177/0022022110396924

Duffy, R. D. (2010). Spirituality, religion, and work values. Journal of Psychology and Theology, 38(1), 52-61.

Duffy, R. D., \& Sedlacek, W. E. (2007). The work values of first-year college students: Exploring group $\begin{array}{llll}\text { differences. The Career Development } & \text { Quarterly, 55(4), }\end{array}$ http://dx.doi.org/10.1002/j.2161-0045.2007.tb00090.x

Elizur, D. (1984). Facets of work values: A structural analysis of work outcomes. The Journal of Applied Psychology, 69(3), 379-389. http://dx.doi.org/10.1037/0021-9010.69.3.379 
Fletcher, T. D., \& Major, D. A. (2004). Medical students' motivations to volunteer: An examination of the nature of gender differences. Sex Roles, 51(1-2), 109-114. http://dx.doi.org/10.1023/B:SERS.0000032319.78926.54

Froese, F. J., \& Xiao, S. (2012). Work values, job satisfaction and organizational commitment in China. The International Journal of Human Resource Management, 23(10), 2144-2162.

Gahan, P., \& Abeysekera, L. (2009). What shapes an individual's work values? An integrated model of the relationship between work values, national culture and self-construal. International Journal of Human Resource Management, 20(1), 126-147. http://dx.doi.org/10.1080/09585190802528524

Hagström, T., \& Kjellberg, A. (2007). Stability and change in work values among male and female nurses and $\begin{array}{lllll}\text { engineers. Scandinavian Journal of Psychology, } & 48(2), & 143-151 .\end{array}$ http://dx.doi.org/10.1111/j.1467-9450.2007.00576.x

Hegney, D., Plank, A., \& Parker, V. (2006). Extrinsic and intrinsic work values: Their impact on job satisfaction in nursing. Journal of Nursing Management, 14(4), 271-281. http://dx.doi.org/10.1111/j.1365-2934.2006.00618.x

Hirschi, A. (2008). Personality complexes in adolescence: Traits, interests, work values, and self-evaluations. Personality and Individual Differences, 45(8), 716-721.

Howell, A., Kirk-Brown, A., \& Cooper, B. K. (2012). Does congruence between espoused and enacted organizational values predict affective commitment in Australian organizations. The International Journal of Human Resource Management, 731-747.

Jin, J., \& Rounds, J. (2012). Stability and change in work values: A meta-analysis of longitudinal studies. Journal of Vocational Behavior, 80(2), 326-339.

Liu, Y., \& Lei, Y. (2012). The connotation of work values: A preliminary review. Asian Social Science, 8(1), 47-53. http://dx.doi.org/10.5539/ass.v8n1p47

Lyons, S. T., Higgins, C., \& Duxbury, L. (2010). Work values: Development of a new three dimensional structure based on confirmatory smallest space analysis. Journal of Organizational Behavior, 31, 969-1002.

Manhardt, P. J. (1972). Job orientation of male and female college graduates in business. Personnel Psychology, $25,361-368$.

Martin, K., \& Osterling, M. (2014). Value Stream Mapping: How to Visualize Work and Align Leadership for Organizational Transformation. New York: Mc Grow Hill.

Roe, R. A., \& Ester, P. (1999). Values and work: Empirical findings and theoretical perspective. Applied Psychology, 48(1), 1-21. http://dx.doi.org/10.1111/j.1464-0597.1999.tb00046.x

Ros, M., Schwartz, S., \& Surkiss, S. (1999). Basic Individual Values, Work Values, and the Meaning of Work. Applied Psychology: An International Review, 48(1), 49-71.

Rounds, J. B., Dawis, R. V., Lofquist, L. H., \& Weis, D. J. (1981). Manual for the Minnesota Importance Questionnaire: A measure of vocational needs and values. Minneapolis, MN: Department of Psychology, University of Minnesota.

Ryckman, R. M., \& Houston, D. M. (2003). Value priorities in American and British female and male university students. The Journal of Social Psychology, 143(1), 127-138. http://dx.doi.org/10.1080/00224540309598435

Super, D. (1995). Values: Their nature, assessment, and practical use. In D. E. Super \& B. Sverko (Eds.), Life roles, values, and careers (pp. 54-61). San Francisco, CA: Jossey-Bass.

Trentini, G., \& Muzio, G. (1995). Values in a cross-cultural perspective: A further analysis. In D. E. Super \& B. Sverko (Eds.), Life roles, values, and careers (pp. 241-251). San Francisco, CA: Jossey-Bass.

Zytowski, D. G. (2006). Super Work Values Inventory-Revised: Technical manual.

\section{Copyrights}

Copyright for this article is retained by the author(s), with first publication rights granted to the journal.

This is an open-access article distributed under the terms and conditions of the Creative Commons Attribution license (http://creativecommons.org/licenses/by/3.0/). 